\title{
Unsupported Copper Nanoparticles in the 1,3-Dipolar Cycloaddition of Terminal Alkynes and Azides
}

\author{
Francisco Alonso, ${ }^{*[a]}$ Yanina Moglie, ${ }^{[a, b]}$ Gabriel Radivoy, ${ }^{[b]}$ and Miguel Yus*[a]
}

Dedicated to Professor Stephen G. Davies on occasion of his 60th birthday

Keywords: Click chemistry / Cycloaddition / Alkynes / Azides / Copper / Nanoparticles

Readily prepared copper nanoparticles were found to catalyse the 1,3-dipolar cycloaddition of azides and alkynes up to rates comparable to those of microwave chemistry. Both the preparation of the nanoparticles and the click reaction are carried out under mild conditions, in short reaction times and in the absence of any stabilising additive or ligand. A variety of 1,2,3-triazoles were prepared in excellent yields. A reaction mechanism was postulated on the basis of different reactivity studies and deuteration experiments. Copper(I) acetylides were demonstrated to be the real intermediate species.

\section{Introduction}

In recent years, much attention has been devoted to the Huisgen 1,3-dipolar cycloaddition reaction of organic azides and alkynes ${ }^{[1]}$ taking advantage of the paramount discovery by the groups of Meldal ${ }^{[2]}$ and Sharpless, ${ }^{[3]}$ who independently reported an unprecedented cycloaddition rate under copper(I) catalysis. In addition, mild reaction conditions could be applied, furnishing exclusively the 1,4-regioisomer of the triazole product. ${ }^{[4]}$ The fulfillment of a series of rigorous requirements, as defined by Sharpless et al., ${ }^{[5]}$ do for it the click reaction par antonomasia.

$((<=$ Author: please check - this last part of this sentence is not clear)) Nowadays, many research fields ${ }^{[4 b, 6]}$ benefit from the high reliability of this reaction, including organic chemistry, ${ }^{[4]}$ drug discovery and medicinal chemistry, ${ }^{[7]}$ polymer ${ }^{[8]}$ and materials science ${ }^{[8 a, 9]}$ and bioconjugation. ${ }^{[7 a, 9,10]}$

Catalyst-free Huisgen cycloadditions ${ }^{[11]}$ have been reported in water, ${ }^{[1 \mathrm{a}, 11 \mathrm{~b}]}$ as well as for particularly substituted

[a] Departamento de Química Orgánica, Facultad de Ciencias and Instituto de Síntesis Orgánica (ISO), Universidad de Alicante, Apdo. 99, 03080 Alicante, Spain

Fax: +34-965903549

E-mail: falonso@ua.es, yus@ua.es

[b] Departamento de Química, Instituto de Química del Sur (INQUISUR-CONICET), Universidad Nacional del Sur, Avenida Alem 1253, 8000 Bahía Blanca, Argentina Fax: +54-2914595187

Supporting information for this article is available on the WWW under http://dx.doi.org/10.1002/ejoc.200901446.

the kinetics and/or the regioselectivity is low, making the copper(I)-catalysed process the preferred choice. Recently, Feringa et al. synthesised various benzotriazoles by a copper-free cycloaddition of azides and arynes, as an interesting variation of the classical 1,3-dipolar cycloaddition. ${ }^{[11 \mathrm{e}]}$ The copper(I)-catalysed cycloaddition is normally accomplished with success independently of the copper source utilised, namely, copper(I) salts, normally in the presence of a base and/or a ligand; in situ reduction of copper(II) salts (e.g., copper sulfate with sodium ascorbate); and comproportionation of copper( 0 ) and copper(II) (generally restricted to biological applications). ${ }^{[4]}$

Despite the fact that the 1,3-dipolar cycloaddition of alkynes and azides has reached an advanced level of development, the introduction of variants that can further improve the efficiency of the reaction and fulfill the requirements of a truly click reaction are welcome. For instance, different ligands were found to promote this cycloaddition reaction by stabilisation of the $\mathrm{Cu}^{\mathrm{I}}$ oxidation state under aerobic and/or aqueous conditions. ${ }^{[12]}$ The in situ generation of the organic azides (three-component reaction) also represents an important advantage, simplifying the experimental procedure and minimising risks derived from handling hazardous azides. ${ }^{[13]}$ The application of microwave chemistry has contributed to dramatically reduce the reaction times from $12-24 \mathrm{~h}$ (for most of the protocols) to less than $1 \mathrm{~h} .{ }^{[14]} \mathrm{Ul}-$ trasound also proved to be an effective technique to shorten the reaction times of the three-component version in water $^{[15]}$ Some other advances in the title reaction involve heterogeneous catalysis. ${ }^{[16]}$ Thus, catalysts based on copper(I) immobilised on different supports, such as charcoal, ${ }^{[16 \mathrm{a}]}$ zeolites, $^{[16 \mathrm{~b}]}$ silica ${ }^{[16 \mathrm{c}]}$ or an ionic polymer, ${ }^{[16 \mathrm{~d}]}$ have 
an added value due to their easy recovery and reutilisation capability. Ley et al. reported the successful cycloaddition of alkynes and azides by using immobilised reagents and scavengers in prepacked glass tubes in a modular flow reactor. ${ }^{[17]}$

In 2005, it was discovered that copper metal turnings or powder, in stoichiometric quantity, could be a source of the catalytic species involved in the title click reaction. ${ }^{[18]}$ Since then, the use of copper nanoparticles (CuNPs), instead of bulk copper, has been increasingly explored to reduce both the catalyst loading and the reaction times. ${ }^{[19]}$ Despite the interesting behaviour unveiled for CuNPs, there are some issues that limit their application, competitiveness and general acceptance that need to be addressed. For instance, most of the methods of preparation of CuNPs are rather tedious due to the multiple steps involved, long reaction time, high temperatures or use of noncommercially available reagents. The presence of stabilising agents or solid supports to prevent nanoparticle agglomeration is mandatory in some cases. The limited substrate scope, as well as the necessity of an acidic medium or the chromatographic purification of the reaction products, are additional disadvantages found in 91 some methodologies. The reaction times, though considerably reduced in some cases, are still relatively long (2-24 h). Recently, several heterogeneous catalysts based on copper nanoparticles have disclosed an interesting reuse capability. Thus, PVP-stabilised CuNPs in formamide were applied to benzyl azide and some aryl azides and reutilised in up to four subsequent runs with high product yields in very short reaction times (15-50 $\mathrm{min})$ at room temperature. ${ }^{[19 \mathrm{e}]}$ Inmobilised CuNPs in aluminium oxyhydroxide nanofibre were shown to be also effective and reusable in $n$-hexane at room 101 temperature, albeit longer reaction times were required (124 h). ${ }^{[19 f]}$ Furthermore, larger copper nanostructures (80$300 \mathrm{~nm}$ ) on charcoal catalysed the three-component click reaction in water at $100^{\circ} \mathrm{C}(0.5-24 \mathrm{~h})$ and could be reused in more than 10 successive reactions. ${ }^{[19 \mathrm{~g}]}$

106 As part of our dedication to study the reactivity of active metals, ${ }^{[20]}$ we discovered that a system composed of copper(II) chloride dihydrate $\left(\mathrm{CuCl}_{2} \cdot 2 \mathrm{H}_{2} \mathrm{O}\right)$, lithium metal and a catalytic amount of 4,4'-di-tert-butylbiphenyl (DTBB) in THF generates active copper with interesting reducing

111 properties. This copper found application in (1) the reduction of carbonyl compounds and imines to alcohols and secondary amines, respectively; ${ }^{[21 a]}$ (2) the hydrodehalogenation of alkyl and aryl fluorides, chlorides, bromides and iodides (including polyhalogenated aromatic com116 pounds); ${ }^{[21 b]}$ and (3) the reduction of alkyl and vinyl sulfonates (including dienol triflates) to alkanes and alkenes, respectively. ${ }^{[21 \mathrm{c}]}$ All these reactions were carried out at room temperature, and deuterated products were easily prepared by using the corresponding deuterated copper salt

$121\left(\mathrm{CuCl}_{2} \cdot 2 \mathrm{D}_{2} \mathrm{O}\right)$. More recently, we observed that $\mathrm{CuNPs}$ are formed under the above-mentioned conditions when using either copper(II) chloride dihydrate or anhydrous copper(II) chloride. In the latter case, the CuNPs were found to effectively catalyse the 1,3-dipolar cycloaddition of az126 ides and terminal alkynes. ${ }^{[2]}$ We wish to present herein a more complete study including a wider substrate scope and some experiments that contribute to clarify the reaction mechanism.

\section{Results and Discussion}

A suspension of CuNPs was instantaneously prepared from anhydrous copper(II) chloride, powder lithium metal, and a catalytic amount of DTBB (10 mol- $\%$, as an electron carrier) in THF at room temperature. This method was proven to be more convenient than that originally developed by Rieke et al., involving the reduction of copper(I) iodide with potassium metal, along with a catalytic amount of naphthalene $(10 \mathrm{~mol}-\%)$ in 1,2-dimethoxyethane. ${ }^{[23]}$ In this case, the extended periods of stirring required $(8-12 \mathrm{~h}$ at room temperature) favoured sintering, leading to a greyblack granular solid suspended in a clear colourless solution.

The aforementioned suspension of the CuNPs was analysed by transmission electron microscopy (TEM), X-ray photoelectron spectroscopy (XPS) and powder X-ray diffraction (XRD). Well-defined spherical nanoparticles were observed by TEM, with a particle size distribution of ca. $3.0 \pm 1.5 \mathrm{~nm}$ (Figure 1). The size of the nanoparticles obtained was smaller than that obtained by using some physical methods ${ }^{[24]}$ or other reducing agents ${ }^{[25]}$ and akin to that attained by the clustering of acetone-solvated copper atoms, ${ }^{[26 a]}$ laser electrodeposition ${ }^{[26 \mathrm{~b}]}$ or microwave-assisted alcohol reduction. ${ }^{[26 c]}$
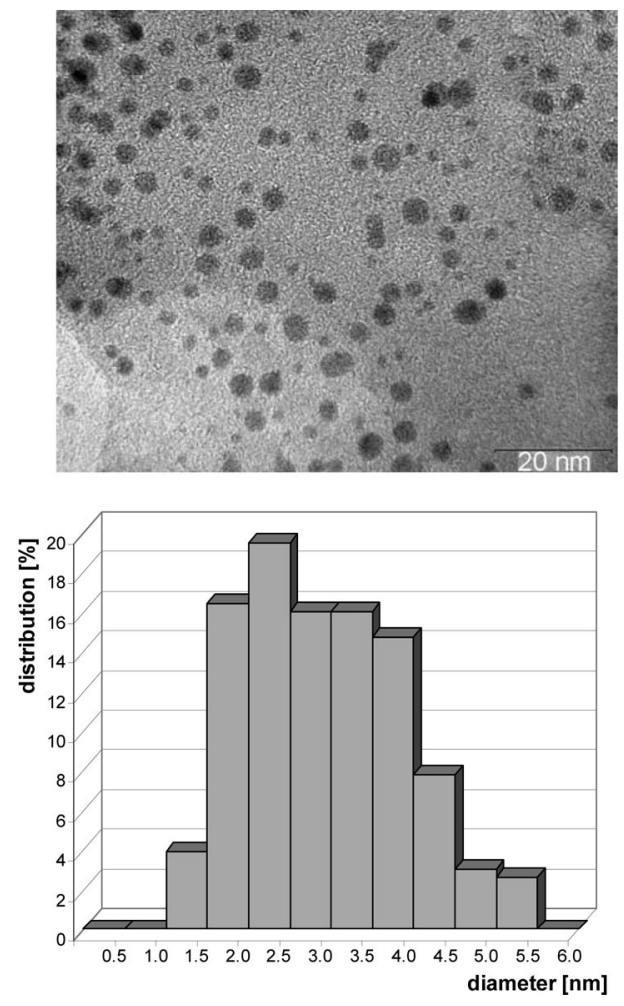

Figure 1. TEM micrograph and size distribution of the CuNPs. The sizes were determined for 230 nanoparticles selected at random. 
Energy-dispersive X-ray (EDX) analysis on various regions confirmed the presence of copper, with energy bands of $8.04,8.90 \mathrm{keV}$ ( $\mathrm{K}$ lines) and $0.92 \mathrm{keV}$ (L line; Figure 2). ${ }^{[27]}$ The XPS spectrum displays a single $\mathrm{Cu} 2 \mathrm{p}_{3 / 2}$ peak at $933.0 \mathrm{eV}$, which in principle, could be ascribed to $\mathrm{Cu}^{0}$, as no significant shoulder peak of $\mathrm{CuO}$ at $934 \mathrm{eV}$ was observed (Figure 3). ${ }^{[28]}$ The oxidation state of copper is, however, difficult to assign on the basis of only XPS studies due to the close proximity of the binding energies of the $\mathrm{Cu}^{0}$, $\mathrm{Cu}^{\mathrm{I}}$ and $\mathrm{Cu}^{\mathrm{II}}$ states. ${ }^{[28]}$ Further information was obtained when a sample was exposed to air for a prolonged time. In this case, two $\mathrm{Cu} 2 \mathrm{p}_{3 / 2}$ peaks at 932.8 and $934.1 \mathrm{eV}$ were observed, with the latter corresponding to $\mathrm{Cu}^{\mathrm{II}}$ in the form of $\mathrm{CuO}$ (Figure 4).
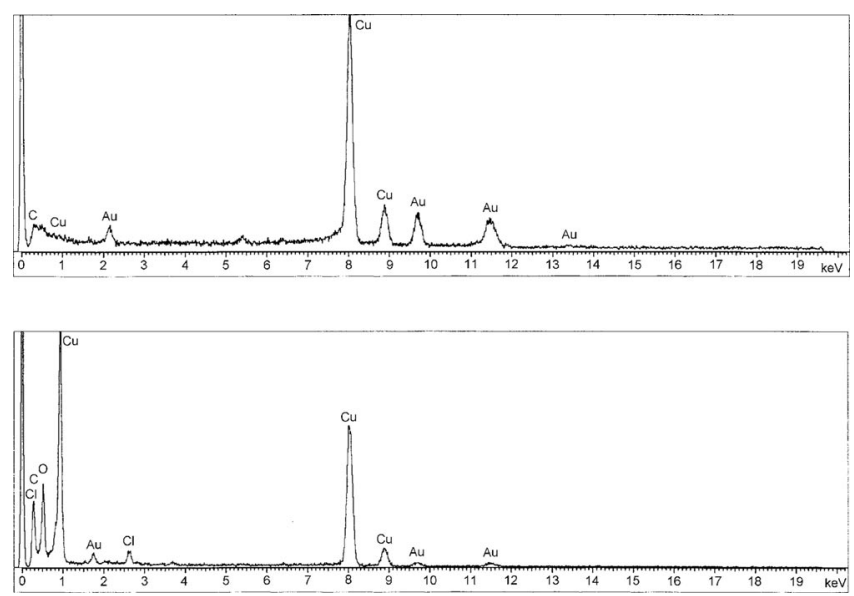

Figure 2. EDX spectra of the CuNPs obtained from two different areas.

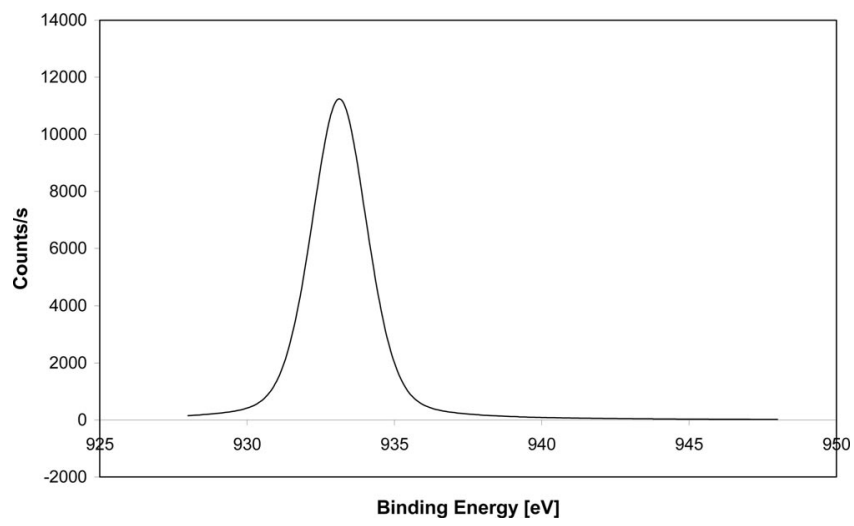

Figure 3. XPS spectrum of the CuNPs.

The XRD spectrum shows peak positions that are consistent with the presence of face-centred-cubic copper (Figure 5). ${ }^{[24 a, 24 b]}$ The additional peaks correspond to lithium chloride formed during the generation of the CuNPs, though formation of small amounts of $\mathrm{Cu}_{2} \mathrm{O}$ in the reaction medium or during sample handling cannot be ruled out. At any rate, peaks corresponding to $\mathrm{CuO}$ were not detected. ${ }^{[28 c]}$ The selected area electron diffraction (SAED) pattern is in agreement with the presence, primarily, of metallic copper (Figure 6). ${ }^{[25 d, 26 c]}$

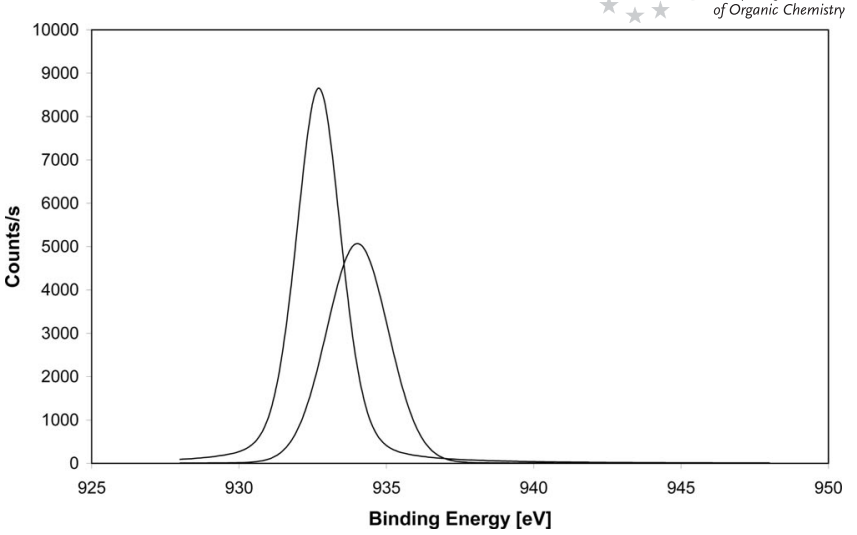

Figure 4. XPS spectrum of the CuNPs exposed to air.

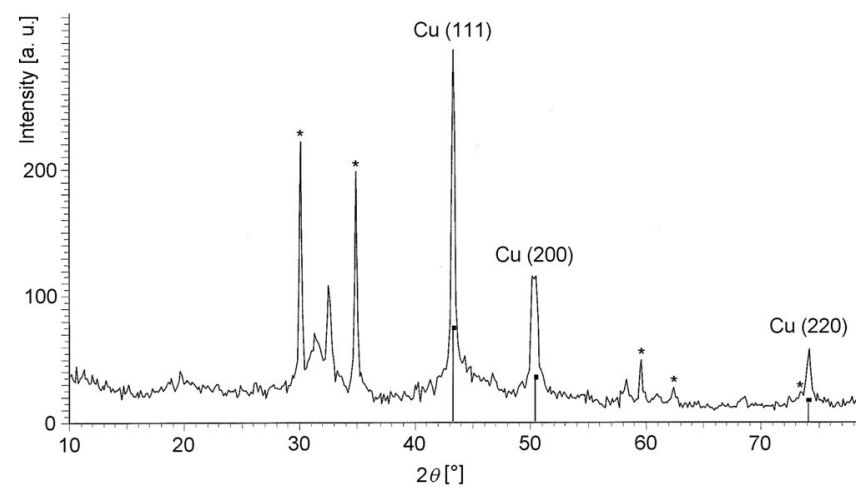

Figure 5. XRD spectrum of the CuNPs (*denotes $\mathrm{LiCl})$.

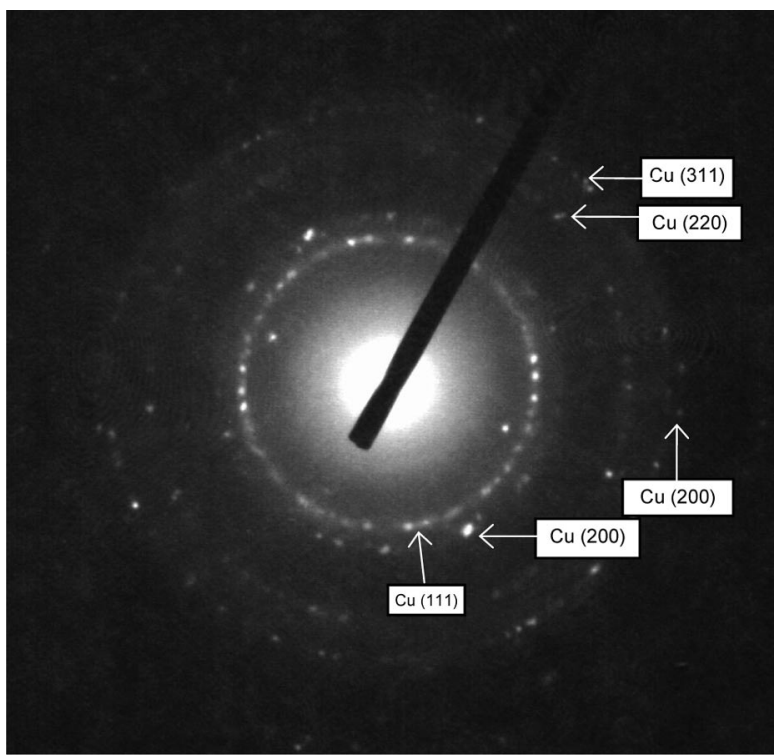

Figure 6. Selected area electron diffraction (SAED) pattern of the CuNPs.

The reaction conditions for the click reaction were optimised by using benzyl azide (1a) and cyclohexylacetylene (2a) as model substrates (Table 1). Two control experiments were carried out under the conditions of generation of the CuNPs but in the absence of the copper salt (with or without $\mathrm{Et}_{3} \mathrm{~N}$ ), leading to starting 1a and 2a. The presence of 
$\mathrm{Et}_{3} \mathrm{~N}$ was shown to be crucial for the reaction to occur (Table 1, Entry 1). The CuNPs, in a stoichiometric amount,

186 were found to be superior to other sources of copper, furnishing 3aa in the highest yield and shortest reaction time (Table 1, Entries 2-8). Excellent yields of 3aa were obtained even by decreasing the amount of CuNPs up to 1 mol- $\%$, albeit longer reaction times were required (Table 1, En191 tries 9-13). Interestingly, a short reaction time of only $30 \mathrm{~min}$ at $25^{\circ} \mathrm{C}$ was recorded by the addition of $>1$ equiv. of $\mathrm{Et}_{3} \mathrm{~N}$, with the yields being also excellent (Table 1, Entries 14 and 15). Unfortunately, this remarkable decrease in time was not so general for some other substrates tested at $25^{\circ} \mathrm{C}$. The same excellent result as aforementioned, however, was obtained when the model reaction was conducted at $65^{\circ} \mathrm{C}$ (Table 1, Entry 16). Under the latter reaction conditions, $\mathrm{CuCl}$ or $\mathrm{CuNPs}$ in the solvent mixture $t \mathrm{BuOH} / \mathrm{H}_{2} \mathrm{O}$ (1:2) or in air led to lower product yields in much longer reaction times (Table 1, Entries 17-20). In view of the above results, we considered the reaction conditions in Entry 16 the most appropriate, providing a method of more general application at the same time that the short reaction time is maintained.

Table 1. Copper-catalysed 1,3-dipolar cycloaddition of benzyl azide and cyclohexylacetylene. ${ }^{[a]}$

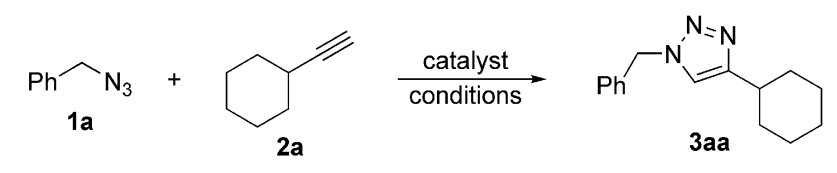

\begin{tabular}{|c|c|c|c|c|c|}
\hline Entry & Catalyst (mmol) & $\begin{array}{l}\text { Additive } \\
(\mathrm{mmol})\end{array}$ & $T\left[{ }^{\circ} \mathrm{C}\right]$ & $t[\mathrm{~h}]$ & Yield $[\%]^{[b]}$ \\
\hline 1 & CuNPs (100) & none & 25 & 12 & 0 \\
\hline 2 & CuNPs (100) & $\mathrm{Et}_{3} \mathrm{~N}(1)$ & 25 & 1 & 98 \\
\hline 3 & $\mathrm{Cu}(100)^{[\mathrm{cc}]}$ & $\mathrm{Et}_{3} \mathrm{~N}(1)$ & 25 & 2 & 0 \\
\hline 4 & $\mathrm{CuO}(100)$ & $\mathrm{Et}_{3} \mathrm{~N}(1)$ & 25 & 2 & 0 \\
\hline 5 & $\mathrm{Cu}_{2} \mathrm{O}(100)$ & $\mathrm{Et}_{3} \mathrm{~N}(1)$ & 25 & 2 & 0 \\
\hline 6 & $\mathrm{CuCl}_{2}(100)$ & $\mathrm{Et}_{3} \mathrm{~N}(1)$ & 25 & 2 & 0 \\
\hline 7 & $\mathrm{CuCl}(100)$ & $\mathrm{Et}_{3} \mathrm{~N}(1)$ & 25 & 3 & $85^{[\mathrm{d}]}$ \\
\hline 8 & CuNPs (100) & $\mathrm{PVP} / \mathrm{Et}_{3} \mathrm{~N}(1)^{[\mathrm{e}]}$ & 25 & 3 & 58 \\
\hline 9 & CuNPs (20) & $\mathrm{Et}_{3} \mathrm{~N}$ & 25 & 6 & 98 \\
\hline 10 & CuNPs (10) & $\mathrm{Et}_{3} \mathrm{~N}(1)$ & 25 & 6 & 98 \\
\hline 11 & CuNPs (5) & $\mathrm{Et}_{3} \mathrm{~N}(1)$ & 25 & 24 & 98 \\
\hline 12 & CuNPs (2) & $\mathrm{Et}_{3} \mathrm{~N}(1)$ & 25 & 24 & 100 \\
\hline 13 & CuNPs (1) & $\mathrm{Et}_{3} \mathrm{~N}(1)$ & 25 & 24 & 100 \\
\hline 14 & CuNPs (10) & $\mathrm{Et}_{3} \mathrm{~N}(3)$ & 25 & 0.5 & 99 \\
\hline 15 & CuNPs (10) & $\mathrm{Et}_{3} \mathrm{~N}(2)$ & 25 & 0.5 & 99 \\
\hline 16 & CuNPs (10) & $\mathrm{Et}_{3} \mathrm{~N}(1)$ & 65 & 0.5 & 100 \\
\hline 17 & $\mathrm{CuCl}(10)$ & $\mathrm{Et}_{3} \mathrm{~N}$ & 25 & 24 & 70 \\
\hline 18 & $\mathrm{CuCl}(10)$ & $\mathrm{Et}_{3} \mathrm{~N}(1)$ & 65 & 24 & 80 \\
\hline 19 & CuNPs (10) & $\mathrm{Et}_{3} \mathrm{~N}(1)^{[\mathrm{f]}]}$ & 65 & 24 & 75 \\
\hline 20 & CuNPs (10) & $\mathrm{Et}_{3} \mathrm{~N}(1)^{[\mathrm{g}]}$ & 65 & 24 & 71 \\
\hline
\end{tabular}

[a] Reaction conditions: 1a $(1 \mathrm{mmol})$ and $\mathbf{2 a}(1 \mathrm{mmol})$ in THF. [b] GLC yield. [c] Cu powder $(1-5 \mu \mathrm{m})$. [d] Multiple side products were detected. [e] $1 \mathrm{~g}$ PVP (MW ca. 29000). [f] Reaction in $t \mathrm{BuOH} /$ $\mathrm{H}_{2} \mathrm{O}, 1: 2$. [g] Reaction in air.

The optimised reaction conditions (Scheme 1) were extended to a variety of azides and terminal alkynes (Tables 2 and 3). We first explored the reactivity of benzyl and phenyl azide. The reaction of benzyl azide (1a) with linear alkylsubstituted terminal alkynes led to the corresponding tri- azoles in $85-98 \%$ yield (Table 2, Entries 2-5). Hex-1-yne (2b) and oct-1-yne (2c) reacted very fast (Table 2, Entries 2 and 3), whereas a progressive increase in the reaction time was observed for the longer alkyl-chain alkynes dec-1-yne (2d) and dodec-1-yne (2e) (Table 2, Entries 4 and 5). Very short reaction times were also recorded for the phenyl-substituted alkynes 4-phenylbut-1-yne (2f) and phenylacetylene $(\mathbf{2 g})$, with the expected products being obtained in high yields (Table 2, Entries 6 and 7). The conjugated alkyne 1ethynylcyclohex-1-ene (2h) behaved similarly to the nonconjugated cyclohexylacetylene (2a) as regards both the reaction time and product yield (Table 2, Entry 8). Two propargylic alcohols were also tested, with prop-2-yn-1-ol (2i) manifesting a better performance than the more sterically demanding 1-ethynylcyclohexanol (2j) (Table 2, Entries 9 and 10). Phenyl azide (1b) exhibited very close reactivity to that previously mentioned for benzyl azide (1a) with alkynes $\mathbf{2} \mathbf{a}, \mathbf{2} \mathbf{b}, \mathbf{2} \mathbf{g}$ and $\mathbf{2} \mathbf{j}$. Thus, the same reaction times and near yields were obtained in all cases except for hex-1-yne (2b), the reaction of which was higher yielding for benzyl azide (1a) (Table 2, Entry 12).

$$
\mathrm{R}_{1}^{1}-\mathrm{N}_{3}+\sum_{2} \mathrm{R}^{2} \stackrel{\operatorname{CuNPs}(10 \mathrm{~mol}-\%)}{\mathrm{Et}_{3} \mathrm{~N}, \mathrm{THF}, 65^{\circ} \mathrm{C}} \quad \mathrm{R}^{1}-\mathrm{N}_{3}^{N}=\mathrm{N}
$$

Scheme 1. General conditions for the CuNPs-catalysed 1,3-dipolar cycloaddition of azides and terminal alkynes.

We next studied the reactivity of various structurally and electronically different azides (Table 3). The linear alkyl and cyclic azides $n$-dodecyl azide (1c) and cyclohexyl azide (1d), respectively, required, in general, longer reaction times with some of the previously assayed alkynes. Nonetheless, the expected triazole products were obtained in good-to-excellent yields (Table 3 Entries 1-5). A similar behaviour was observed for the electron-deficient aryl azide 4-azidoacetophenone (1e), which was shown to be less reactive than the electronically neutral phenyl azide (1b) (Table 2, Entries 12 and 14 vs. Table 3, Entries 6 and 8, respectively). Ethyl 2-azidoacetate (1f) readily reacted with phenyl acetylene (2c) and 1-ethynylcyclohex-1-ene (2h), though in the latter case the triazole yield was below the average (Table 3, Entries 9 and 10). Allylic cinnamyl azide (1g) provided excellent yields of five different triazoles, with the reaction times ranging from 10 to $120 \mathrm{~min}$ (Table 3, Entries 11-15). Under these reaction conditions, cinnamyl azide did not undergo a [3,3]-sigmatropic rearrangement leading to the secondary allylic azide, ${ }^{[29]}$ as compounds 3ga, 3gb, 3gc, $\mathbf{3 g f}$ and 3gh were the only detected products.

It is worthy to mention that, under the standard conditions, all reactions were highly regioselective towards the 1,4-disubstituted triazoles and completed in 10-120 min. Simple workup operations involving filtration and crystallisation or solvent evaporation were generally applied, furnishing the corresponding 1,2,3-triazoles in excellent isolated yields. The short reaction times needed are comparable to those of the methodologies involving microwave chemistry but under milder conditions (65 vs. 75- 
Table 2. 1,3-Dipolar cycloaddition of benzyl and phenyl azide with terminal alkynes catalysed by CuNPs. ${ }^{[a]}$

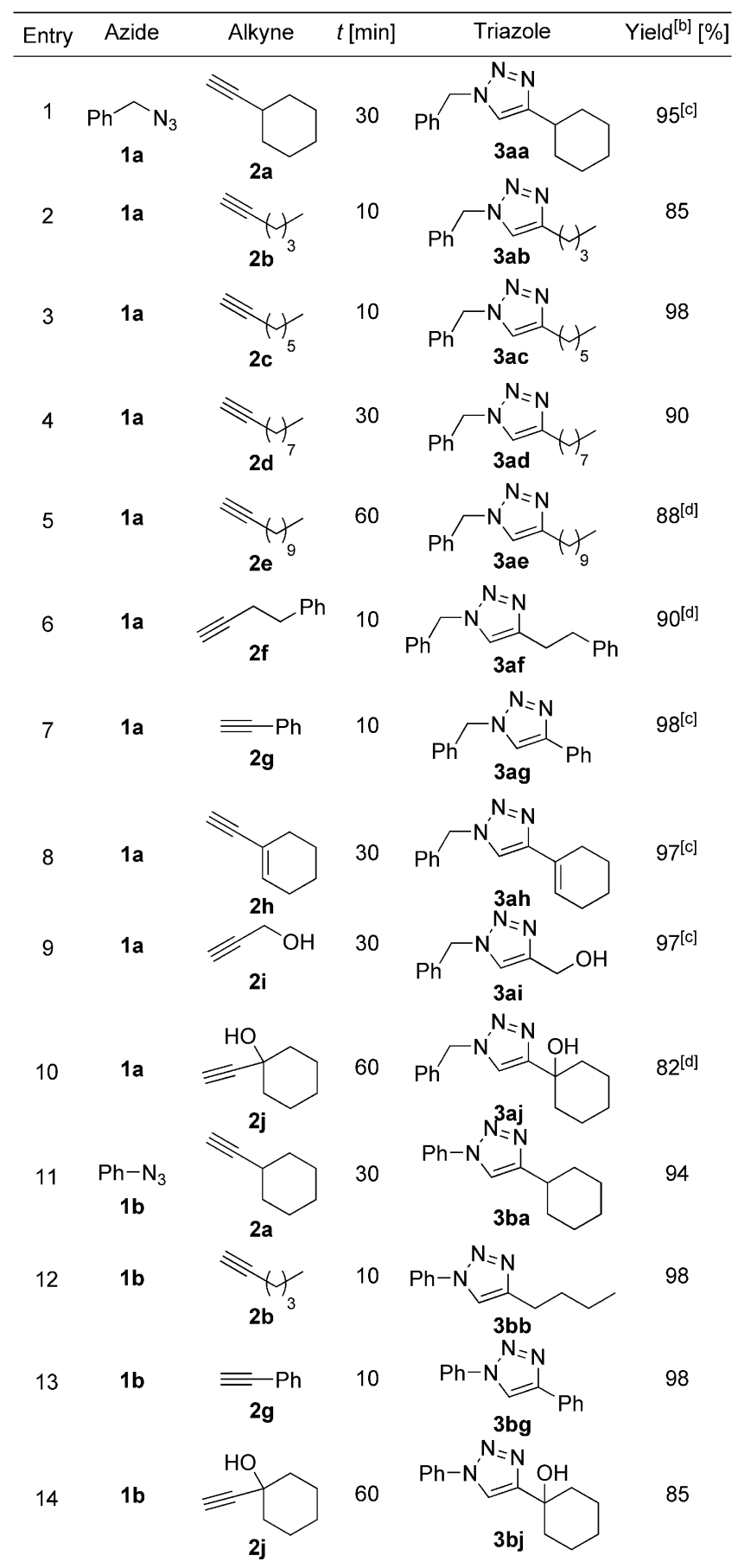

[a] Reaction conditions: 1 (1 mmol), $\mathbf{2}$ (1 mmol), CuNPs (10 mol$\%), \mathrm{Et}_{3} \mathrm{~N}(1 \mathrm{mmol})$ in $\mathrm{THF}$ at $65^{\circ} \mathrm{C}$. [b] Isolated yield after crystallisation in $\mathrm{Et}_{2} \mathrm{O}$ unless otherwise stated. [c] Isolated yield after filtration and solvent evaporation. [d] Isolated yield after column chromatography.

$\left.140{ }^{\circ} \mathrm{C}\right) .{ }^{[14]}$ In fact, some of the 10 -min reactions were thoroughly monitored and found to proceed almost instantaneously (during the first minute), although a standard time of $10 \mathrm{~min}$ was used. This methodology was proven to be
Table 3. 1,3-Dipolar cycloaddition of various azides with terminal alkynes catalysed by CuNPs. ${ }^{[a]}$

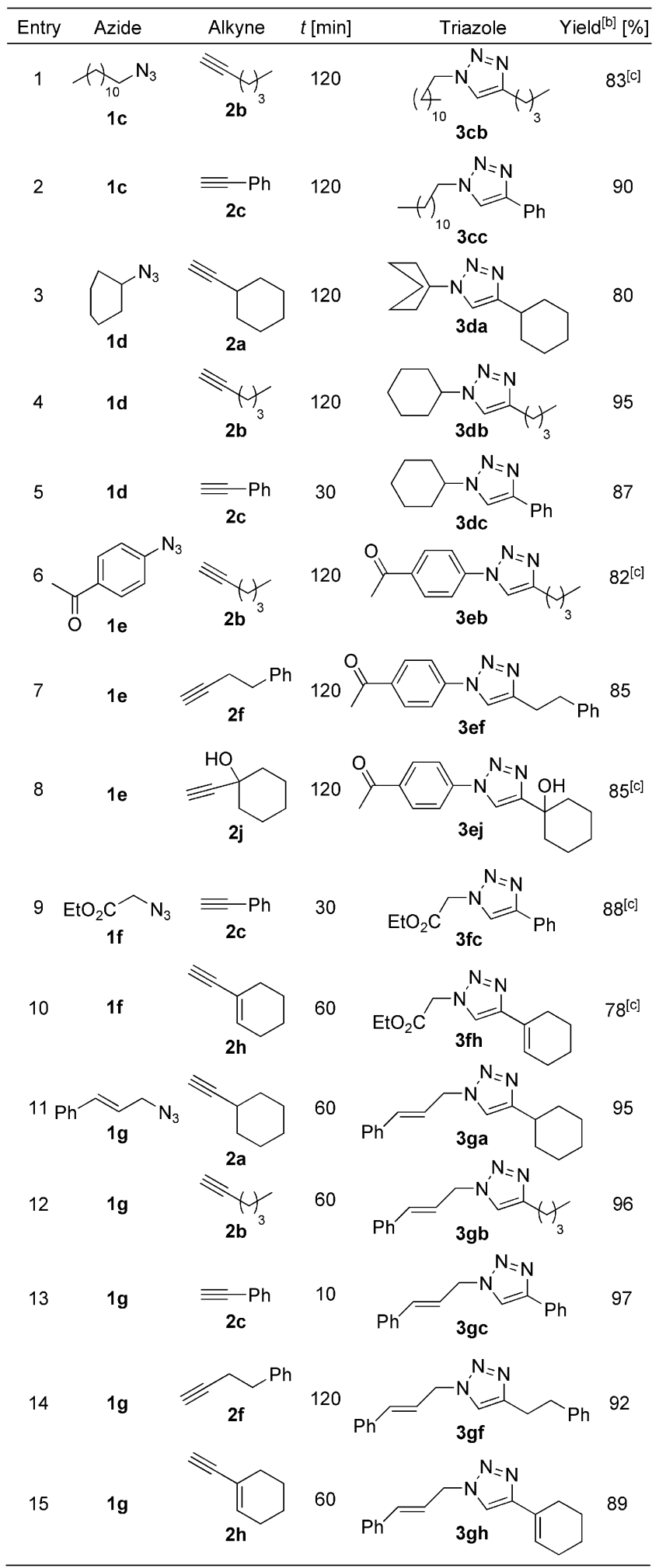

[a] Reaction conditions: 1 ( $1 \mathrm{mmol}), \mathbf{2}(1 \mathrm{mmol}), \mathrm{CuNPs}(10 \mathrm{~mol}-$ $\%), \mathrm{Et}_{3} \mathrm{~N}(1 \mathrm{mmol})$ in $\mathrm{THF}$ at $65^{\circ} \mathrm{C}$. [b] Isolated yield after crystallisation in $\mathrm{Et}_{2} \mathrm{O}$. [c] Isolated yield after filtration and solvent evaporation. 
ethynyloestradiol (2k), which was subjected to the standard procedure with benzyl azide to afford the corresponding triazole-substituted steroid derivative in, practically, quantitative yield after $30 \mathrm{~min}$ (Scheme 2). Moreover, a double 1,3dipolar cycloaddition reaction took place when starting from 1,6-heptadiyne (2l), giving bistriazole product 3al in good yield after $2 \mathrm{~h}$ (Scheme 3 ). The regioselectivity of the process was unequivocally established by X-ray crystallography of 3al (Figure 7). ${ }^{[30]}$<smiles>C#C[C@]1(O)CC[C@H]2[C@H]3CCc4cc(O)ccc4[C@@H]3CC[C@]21C</smiles>

2k
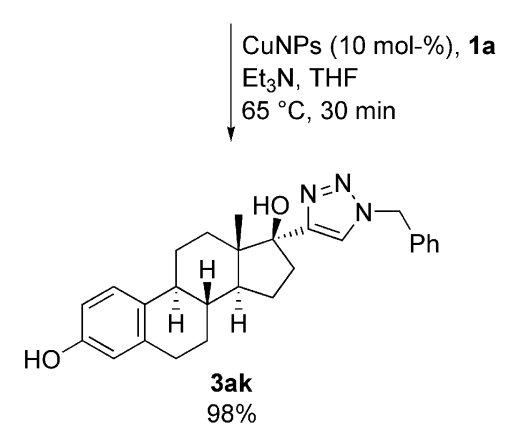

Scheme 2. 1,3-Dipolar cycloaddition of 17a-ethynyloestradiol and $1 \mathrm{a}$.

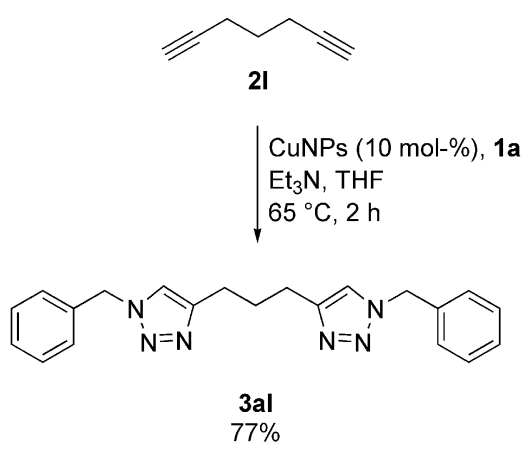

Scheme 3. 1,3-Dipolar cycloaddition of diyne $\mathbf{2 l}$ and $\mathbf{1 a}$.

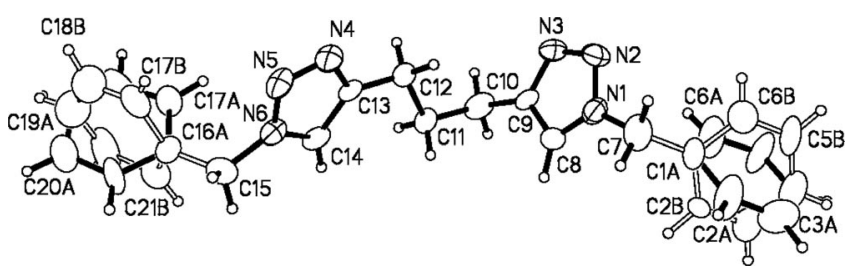

Figure 7. Plot showing the X-ray structure and atomic numbering of bistriazole 3al. The disorder of the phenyl groups in 3al (shown with a different type of bond) was solved by splitting these groups over two positions with $50 \%$ occupancy each. ${ }^{[30]}$

Unfortunately, the CuNPs could not be recovered at the end of the reaction due to the homogeneous nature of the resulting mixture (colourless solution). Some other aliquots of the original suspension of the CuNPs, however, when aged for $5 \mathrm{~d}$, were successfully used in additional experiments, with a decrease in activity being observed after the 10th day (Scheme 4).

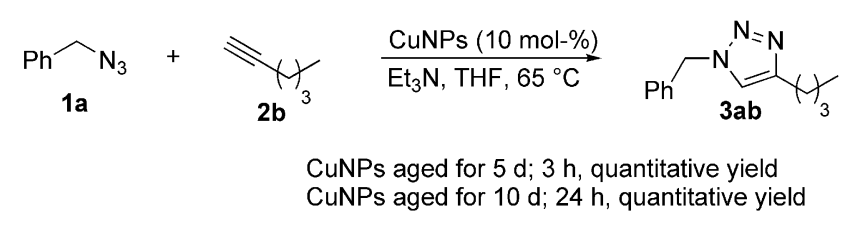

Scheme 4. 1,3-Dipolar cycloaddition of $\mathbf{1 a}$ and $\mathbf{2 b}$ after aging the suspension of the CuNPs.

The reaction mechanism of the alkyne-azide cycloaddition catalysed by copper nanoparticles is not well understood. ${ }^{[19]}$ The formation of copper(I) acetylide is generally invoked (but not demonstrated) by dissolution of $\mathrm{Cu}^{0}$ to $\mathrm{Cu}^{\mathrm{I}}$ or by reaction with $\mathrm{Cu}^{\mathrm{I}}$ on the nanoparticle surface. We gained insight into the reaction mechanism from various observations and a series of experiments: (1) A colourless solution was obtained at the end of the reaction, which changed to a blue colour after addition of an ammonia solution; these assays point to a resulting colourless solution essentially containing $\mathrm{Cu}^{\mathrm{I}}$ ions, the disproportionation of which would be prevented in THF. (2) Dissolution of CuNPs did not occur under the standard conditions in the absence of $\mathrm{Et}_{3} \mathrm{~N}$. (3) Neither $\mathrm{Et}_{3} \mathrm{~N}$ nor the triazole product exhibited any capability of dissolution over the CuNPs by themselves. (4) The suspension of the CuNPs in the presence of $\mathrm{Et}_{3} \mathrm{~N}$ and phenylacetylene, but in the absence of the azide, led to a colourless supernatant and a yellow precipitate (insoluble in water or diethyl ether) that could be attributed to copper(I) phenylacetylide ${ }^{[31]}$ [Scheme 5, Equation (1)]. The amine was suggested to have a double role, promoting the formation of the anion and stabilising the $\mathrm{Cu}^{\mathrm{I}}$ species. ${ }^{[16 \mathrm{a}]}$ The easy formation of the phenylacetylide anion by the action of $\mathrm{Et}_{3} \mathrm{~N}$, under the cycloaddition conditions (THF, $65^{\circ} \mathrm{C}$ ), was demonstrated by deuteration experiments [Scheme 5, Equation (2)]. A sequential process was performed including the reaction of phenylacetylene with $\mathrm{Et}_{3} \mathrm{~N}$, followed by the reaction with the CuNPs and final addition of $\mathrm{BnN}_{3}$ [Scheme 5, Equation (3)]. Under these conditions, the reaction was slower and afforded the expected triazole in $47 \%$ after $1 \mathrm{~h}$ and reached completion after $5 \mathrm{~h}$. In order to find an explanation for the colourless solution obtained at the end of the reaction, a black suspension of the CuNPs was subjected to the action of $\mathrm{Et}_{3} \mathrm{NHCl}$ in THF [Scheme 5, Equation (4)]. Rapid dissolution of the nanoparticles was observed, leading to a colourless solution that should be mainly composed of $\mathrm{CuCl}$. No change in the appearance of this solution was observed after the addition of phenylacetylene. The addition of an excess amount of $\mathrm{Et}_{3} \mathrm{~N}$, however, instantaneously generated a yellow precipitate of copper(I) phenylacetylide. According to all these experiments, it could be inferred that copper(I) acetylides are very likely the real intermediate species in the reactions reported herein. 


$$
\underset{\mathbf{2 g}}{\mathrm{Ph}}=\frac{\operatorname{CuNPs}(10 \mathrm{~mol}-\%)}{\mathrm{Et}_{3} \mathrm{~N}, \mathrm{THF}, 65^{\circ} \mathrm{C}} \quad \underset{\text { yellow precipitate }}{\mathrm{Ph}}
$$

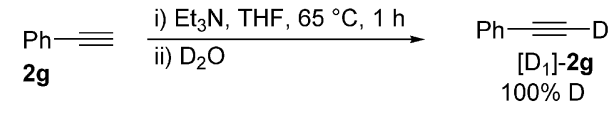

$$
\begin{aligned}
& \mathrm{Ph}=\frac{\text { i) } \mathrm{Et}_{3} \mathrm{~N}, \mathrm{THF}, 65^{\circ} \mathrm{C}, 1 \mathrm{~h}}{\text { ii) } 10 \mathrm{~mol}-\% \mathrm{CuNPs}, 65^{\circ} \mathrm{C}} \\
& \text { iii) } \mathrm{BnN}_{3}, 65^{\circ} \mathrm{C}, 1 \text { or } 5 \mathrm{~h} \quad 3 \text { ag } \\
& 1 \mathrm{~h}, 47 \% \\
& 5 \mathrm{~h}, 100 \%
\end{aligned}
$$

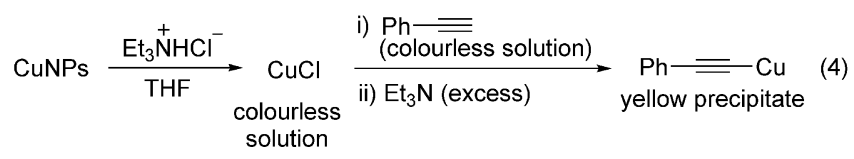

Scheme 5. Different experiments demonstrating the formation of copper(I) phenylacetylide under the cycloaddition reaction conditions.

Notwithstanding the aforementioned results, we performed an additional experiment to bring out further evidence on the in situ formation of the intermediate copper(I) acetylides. Thus, the Sonogashira reaction, a cross-coupling reactions that is well known to proceed through intermediate copper(I) acetylides, was studied. ${ }^{[32]} 1$-Hexyne (2b) was treated with phenyl iodide and a catalytic amount of $\mathrm{PdCl}_{2}\left(\mathrm{PPh}_{3}\right)_{2}$ under the standard cycloaddition reaction conditions in the absence of the azide (Scheme 6). Coupled product 4 was obtained in $33 \%$ yield, indicating that the formation of the intermediate copper(I) acetylide also occurs to some extent.

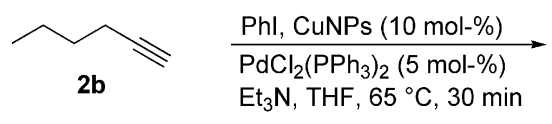

Scheme 6. The CuNPs-catalysed Sonogashira reaction of hex-1-yne and phenyl iodide under the cycloaddition reaction conditions.

The general mechanism for the copper(I)-catalysed 1,3dipolar cycloaddition of alkynes and azides is still a subject of intense debate. ${ }^{[18 \mathrm{a}, 33]}$ Although the formation a molecular copper(I) triazolide complex has been often postulated, only recently, Straub et al. isolated this type of complex as direct evidence for the existence of such structures as intermediates in the click reaction. ${ }^{[33 \mathrm{c}]}$ Final protonolysis of this type of intermediate would afford the triazole product. This step is supposed to occur either in situ, when the reaction is carried out in an aqueous medium (e.g., $\mathrm{H}_{2} \mathrm{O} / t \mathrm{BuOH}$ mixtures), or after aqueous workup. A different reaction mechanism, parallel to that of the Meldal-Sharpless version, has been recently suggested for the click reaction performed with copper(I) zeolites. ${ }^{[16 \mathrm{~b}]}$ In this parallel mechanism, the formation of copper(I) acetylide intermediates was discarded on the basis of the fact that, if such species were formed inside the zeolites, then deuterioalkynes would not give deuterated triazoles. We also performed several deuteration experiments with benzyl azide (1a) and phenyl- acetylene (2g), which produced the following interesting results (Scheme 7). A standard reaction quenched with $\mathrm{D}_{2} \mathrm{O}$ led to nondeuterated triazole 3ag [Scheme 7, Equation (1)]. As expected, deuterated triazole $\left[\mathrm{D}_{1}\right]-3 \mathrm{ag}$ was obtained when deuterated alkyne $\left[\mathrm{D}_{1}\right]-\mathbf{2 g}$ was subjected to the cycloaddition reaction followed by deuteriolysis [Scheme 7, Equation (2)]. In a third experiment, near-to-quantitative deuterium incorporation was achieved when the reaction with $\left[D_{1}\right]-2 g$ was filtered through Celite at the end [Scheme 7, Equation (3)]. From these experiments it could be deduced that the protonolysis/deuteriolysis of the intermediate copper(I) triazolide complex occurs in situ, with the proton/deuterium transfer from the alkyne being very efficient.

$$
\begin{aligned}
& \mathrm{Ph}_{\mathbf{1 a}} \widehat{\mathrm{N}}_{3}+\equiv_{\mathbf{2 g}} \mathrm{Ph} \quad \stackrel{\begin{array}{l}
\text { i) } \operatorname{CuNPs}(10 \mathrm{~mol}-\%) \\
\mathrm{Et}{ }_{3} \mathrm{~N}, \mathrm{THF}, 65^{\circ} \mathrm{C}
\end{array}}{\text { ii) } \mathrm{D}_{2} \mathrm{O}}
\end{aligned}
$$

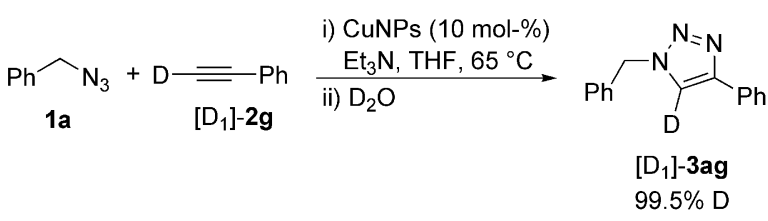

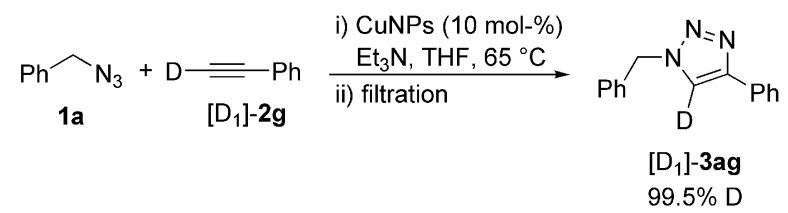

Scheme 7. Deuteration experiments in the CuNPs-catalysed 1,3-dipolar cycloaddition of benzyl azide (1a) and hex-1-yne (2b).

A reaction mechanism for the CuNP-catalysed 1,3-dipolar cycloaddition of terminal alkynes and azides is outlined on the basis of all the previously described experiments (Scheme 8). Deprotonation of the acetylene could occur at a first stage, which in the presence of the lithium chloride derived from the preparation of the CuNPs would form triethylammonium chloride. The action of the latter on the CuNPs could induce the in situ generation of copper(I) chloride, which in turn would react with acetylide species to furnish the corresponding copper(I) acetylide. It is known that copper(I) acetylides can be prepared from ammoniacal copper(I) iodide and acetylenes and that the generation of fresh solutions of copper(I) salts results in acetylides with higher purities. ${ }^{[34]}$ This fact could explain the lower catalytic activity observed for the cycloaddition reaction when using commercial $\mathrm{CuCl}$ in comparison with that using CuNPs (Table 1, Entries 2 and 16 vs. 7 and 18, respectively). It is also known that triethylamine can form a 1:1 complex with anhydrous copper(I) chloride ${ }^{[35]}$ and that, therefore, it could play an additional role in the click reaction to stabilise the $\mathrm{Cu}^{\mathrm{I}}$ species. From this point, the reaction mechanism would follow the original stepwise pathway published by Noodleman, Sharpless, and Fokin et al., ${ }^{[17 a]}$ 口 $((<=$ Author: please check - ref $17 \mathrm{a}$ is not in the refer- 


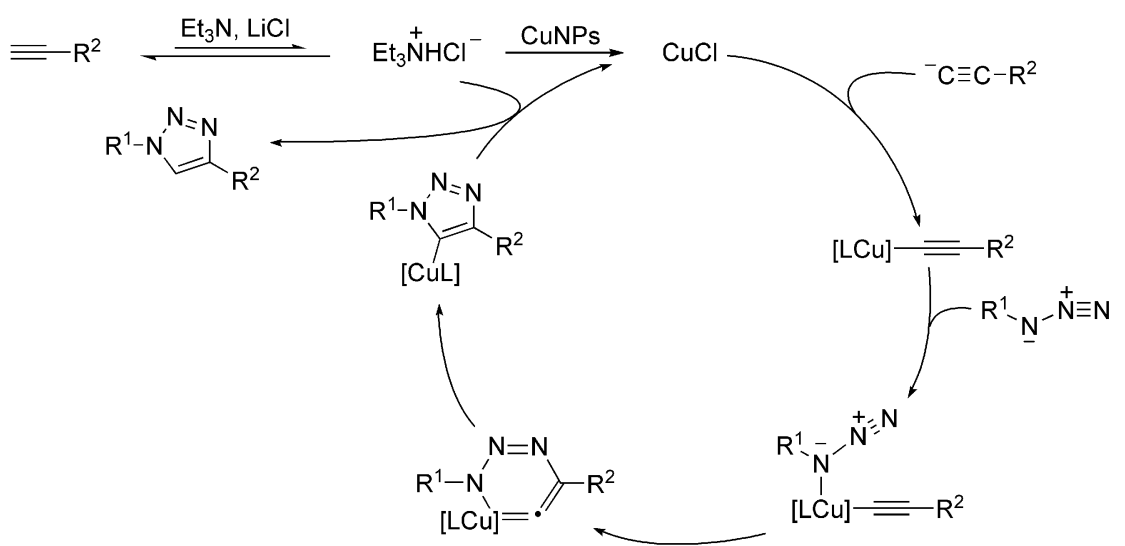

Scheme 8. Reaction mechanism proposed for the CuNPs-catalysed 1,3-dipolar cycloaddition of terminal alkynes and azides.

ences section)) $\mathbf{\square}$ namely, (1) replacement of one ligand in the copper(I) acetylide by the azide, (2) attack of the distal nitrogen of the azide to the C-2 carbon of the acetylide to give a six-membered copper(III) metallacycle and (3) ring contraction to afford a copper(I) triazolide complex. Final protonolysis of the latter by triethylammonium chloride would render the triazole product and regenerate copper(I) chloride.

\section{Conclusions}

Unsupported copper nanoparticles have been easily and rapidly generated from anhydrous copper(II) chloride, lithium metal and a catalytic amount of DTBB as an electron carrier, in the absence of any stabilising additive or ligand. These nanoparticles have been found to catalyse the 1,3dipolar cycloaddition of azides and terminal alkynes in the presence of triethylamine by using THF as solvent at $65^{\circ} \mathrm{C}$. All reactions tested were accomplished in short reaction times (10-120 $\mathrm{min}$ ) and rendered the corresponding triazoles in good-to-excellent isolated yields. The copper nanoparticles in THF exhibited superior catalytic activity when compared with other commercially available copper sources. On the basis of different observations, reactions and deuteration experiments, a reaction mechanism was postulated in which copper(I) acetylides appear as the true intermediate species.

\section{Experimental Section}

Typical Procedure for the Preparation of CuNPs: Anhydrous copper(II) chloride (135 mg, $1 \mathrm{mmol}$ ) was added over a suspension of lithium (14 $\mathrm{mg}, 2 \mathrm{mmol}$ ) and 4,4'-di-tert-butylbiphenyl (DTBB, $27 \mathrm{mg}, 0.1 \mathrm{mmol})$ in THF $(2 \mathrm{~mL})$ at room temperature under an atmosphere of argon. The reaction mixture, which was initially dark blue, rapidly changed to black, indicating that the suspension of the CuNPs was formed. This suspension was diluted by further addition of THF $(8 \mathrm{~mL})$.

General Procedure for the CuNP-Catalysed 1,3-Dipolar Cycloaddition of Azides and Alkynes: $\mathrm{Et}_{3} \mathrm{~N}$ ( 1 equiv.), the azide ( 1 equiv.) and the alkyne (1 equiv.) were added over a suspension of the CuNPs $(10 \mathrm{~mol}-\%)$ in THF under an atmosphere of argon. The reaction mixture was warmed up to $65^{\circ} \mathrm{C}$ and monitored by TLC until total conversion of the starting materials. The resulting solution was passed through a pad of Celite or alternatively subjected to aqueous workup and extraction with EtOAc. The organic phase was dried with $\mathrm{MgSO}_{4}$, and the solvent was removed in vacuo to give the corresponding triazole, which was pure enough or was purified by crystallisation $\left(\mathrm{Et}_{2} \mathrm{O}\right)$ or column chromatography (hexane/EtOAc) (see footnotes in Tables 2 and 3).

1-Benzyl-4-cyclohexyl-1 $\boldsymbol{H}$-1,2,3-triazole (3aa): Yellow solid (95\%), m.p. $110.2-112.0^{\circ} \mathrm{C} ; t_{\mathrm{R}}=13.62, \boldsymbol{\square}((<=$ Author: please provide units and further details, i.e., is this HPLC data?)) $R_{\mathrm{f}}=0.58$ (hexane/EtOAc, 8:2). ${ }^{1} \mathrm{H}$ NMR (400 MHz, $\mathrm{CDCl}_{3}$ ): $\delta=7.41-7.22$ (m, $5 \mathrm{H}, \mathrm{Ar}), 7.16(\mathrm{~s}, 1 \mathrm{H}, \mathrm{CH}), 5.48\left(\mathrm{~s}, 2 \mathrm{H}, \mathrm{CH}_{2}\right), 2.80-2.67(\mathrm{~m}, 1$ $\mathrm{H}, \mathrm{CH}), 2.10-1.15\left(\mathrm{~m}, 10 \mathrm{H}, 5 \times \mathrm{CH}_{2}\right) \mathrm{ppm} .{ }^{13} \mathrm{C} \mathrm{NMR}(100 \mathrm{MHz}$, $\left.\mathrm{CDCl}_{3}\right): \delta=154.1,134.9,128.9,128.5,127.8,119.1,53.8,35.3$, 32.9, 26.1, $25.9 \mathrm{ppm}$. IR (KBr): $\tilde{v}=3118,2918,2844,1539,1495$, $1452,1050,755,703 \mathrm{~cm}^{-1}$. GC-MS (EI): $\mathrm{m} / z(\%)=241(12)[\mathrm{M}]^{+}$, 122 (13), 91 (100). HRMS (EI): calcd. for $\mathrm{C}_{15} \mathrm{H}_{19} \mathrm{~N}_{3}$ 241.1579; found 241.1577 .

Selected X-ray Data for Compound 3al: ${ }^{[30]} \mathrm{C}_{21} \mathrm{H}_{22} \mathrm{~N}_{6}, M=358.45$; monoclinic, $a=9.705(8) \AA, b=6$ 5.054(4) $\AA, c=39.65(3) \AA, \beta=$ $90.923(16)^{\circ} ; V=1945(3) \AA^{3}$; space group $C 2 ; Z=4 ; D_{\text {calcd. }}=$ $1.224 \mathrm{Mg} \mathrm{m}^{-3} ; \lambda=0.71073 \AA ; \mu=0.077 \mathrm{~mm}^{-1} ; F(000)=760 ; T=$ $22 \pm 1^{\circ} \mathrm{C}$.

Supporting Information (see also the footnote on the first page of this article): General experimental details, methods and compound characterisation data.

\section{Acknowledgments}

This work was generously supported by the Spanish Ministerio de Educación y Ciencia (MEC) (grant no. CTQ2007-65218 and Consolider Ingenio 2010-CSD2007-00006), the Generalitat Valenciana (grant no. PROMETEO/2009/039) and the Secretaría General de Ciencia y Tecnología (SeCyT), Universidad Nacional del Sur (PGI 24/Q014). Y.M. thanks the SeCyT of the Universidad Nacional del Sur and the Vicerrectorado de Investigación, Desarrollo e Innovación, Universidad de Alicante for a grant. We are also grateful to J.A. Sirvent (Universidad de Alicante) for carrying out some assays related to the reaction mechanism.

[1] a) R. Huisgen, G. Szeimies, L. Moebius, Chem. Ber. 1965, 98, 4014 4021; b) R. Huisgen, Pure Appl. Chem. 1989, 61, 613628. 
[2] C. W. Tornøe, C. Christensen, M. Meldal, J. Org. Chem. 2002, 67, 3057-3064.

[3] V. V. Rostovtsev, L. G. Green, V. V. Fokin, K. B. Sharpless, Angew. Chem. Int. Ed. 2002, 41, 2596-2599.

[4] For recent reviews, see: a) V. D. Bock, H. Hiemstra, J. H. van Maarseveen, Eur. J. Org. Chem. 2006, 51-68; b) M. Meldal, C. W. Tornøe, Chem. Rev. 2008, 108, 2952-3015.

[5] For a review, see: H. C. Kolb, M. G. Finn, K. B. Sharpless, Angew. Chem. Int. Ed. 2001, 40, 2004-2021.

[6] For general reviews, see: a) M. V. Gil, M. J. Arévalo, O. López, Synthesis 2007, 1589-1620; b) J. E. Moses, A. D. Moorhouse, Chem. Soc. Rev. 2007, 36, 1249-1262; c) see also the special issue on Click Chemistry: QSAR Comb. Sci. 2007, vol. 26, iss. 11 and 12, pp. 1115-1326.

[7] For reviews, see: a) H. C. Kolb, K. B. Sharpless, Drug Discovery Today 2003, 8, 1128-1137; b) G. C. Tron, T. Pirali, R. A. Billington, P. L. Canonico, G. Sorba, A. A. Genazzani, Med. Res. Rev. 2008, 28, 278-308; c) A. D. Moorhouse, J. E. Moses, ChemMedChem 2008, 3, 715-723; d) C. Mamat, T. Ramenda, F. R. Wuest, Mini-Rev. Org. Chem. 2009, 6, 21-34; e) M. D. Best, Biochemistry 2009, 48, 6571-6584; K. New, M. W. Brechbiel, Cancer Biother. Radiopharm. 2009, 24, 289-302.

[8] For reviews, see: a) J.-F. Lutz, Angew. Chem. Int. Ed. 2007, 46, 1018-1025; b) D. Fournier, R. Hoogenboom, U. S. Schubert, Chem. Soc. Rev. 2007, 36, 1369-1380; c) J. A. Johnson, M. G. Finn, J. T. Koberstein, N. J. Turro, Macromol. Rapid Commun. 2008, 29, 1052-1072; d) L. Billiet, D. Fournier, F. Du Prez, Polymer 2009, 50, 3877-3886; e) C. Barner-Kowollik, A. J. Inglis, Macromol. Chem. Phys. 2009, 210, 987-992.

[9] For reviews, see: a) H. Nandivada, X. Jiang, J. Lahann, $A d v$. Mater. 2007, 19, 2197-2208; b) I. Aprahamian, O. Š. Miljanić, W. R. Dichtel, K. Isoda, T. Yasuda, T. Kato, J. F. Stoddart, Bull. Chem. Soc. Jpn. 2007, 80, 1856-1869; c) T. P. Lodge, Macromolecules 2009, 42, 3827-3829; d) G. Franc, A. K. Kakkar, Chem. Eur. J. 2009, 15, 5630-5639; e) J. Lahann (Ed.), Click Chemistry for Biotechnology and Materials Science, Wiley, Chichester, 2009.

[10] For reviews, see: a) A. Dondoni, Chem. Asian J. 2007, 2, 700708; b) Y. L. Angell, K. Burgess, Chem. Soc. Rev. 2007, 36, 1674-1689; c) S. Dedola, S. A. Nepogodiev, R. A. Field, Org. Biomol. Chem. 2007, 5, 1006-1017; d) J.-F. Lutz, Z. Zarafshani, Adv. Drug Delivery Rev. 2008, 60, 958-970; e) S. Bräse, A. Friedrich, M. Gartner, T. Schröder, Top. Heterocycl. Chem. 2008, 12, 45-115; f) F. Amblard, J. H. Cho, R. F. Schinazi, Chem. Rev. 2009, 109, 4207-4220; g) T. Kodadek, Nat. Chem. 2009, 1, 183-185.

521 [11] a) Z. Li, T. S. Seo, J. Ju, Tetrahedron Lett. 2004, 45, 3143-3146; b) P. Li, L. Wang, Lett. Org. Chem. 2007, 4, 23-26; c) N. J. Agard, J. A. Prescher, C. R. Bertozzi, J. Am. Chem. Soc. 2004, 126, 15046-15047; d) J.-F. Lutz, Angew. Chem. Int. Ed. 2008, 47, 2182-2184; e) L. Campbell-Verduyn, P. H. Elsinga, L. Mirfeizi, R. A. Dierckx, B. L. Feringa, Org. Biomol. Chem. 2008, 6, 3461-3463; f) for a recent review, see: C. Remzi Becer, R. Hoogenboom, U. S. Schubert, Angew. Chem. Int. Ed. 2009, 48, $4900-4908$.

[12] See, for instance: a) T. R. Chan, R. Hilgraf, K. B. Sharpless, V. V. Fokin, Org. Lett. 2004, 6, 2853-2855; b) B. Gerard, J. Ryan, A. B. Beeler, J. A. Porco Jr., Tetrahedron 2006, 62, 64056411; c) S. Díez-González, S. P. Nolan, Synlett 2007, 21582167; d) S. Díez-González, S. P. Nolan, Aldrichimica Acta 2008, 41, 47-51; e) N. Candelon, D. Lastécouères, A. Khadri Diallo, J. Ruiz Aranzaes, D. Astruc, J.-M. Vincent, Chem. Commun. 2008, 741-743; f) F. Wang, H. Fu, Y. Jiang, Y. Zhao, Green Chem. 2008, 10, 452-456.

[13] See, for instance: a) K. Odlo, E. A. Høydahl, T. V. Hansen, Tetrahedron Lett. 2007, 48, 2097-2099; b) K. Barral, A. D. Moorhouse, J. E. Moses, Org. Lett. 2007, 9, 1809-1811; c) B. Saha, S. Sharma, D. Sawant, B. Kundu, Synlett 2007, 1591-1594; d) K. Yamaguchi, M. Kotani, K. Kamata, N. Mizuno, Chem. Lett. 2008, 37, 1258-1259.
[14] See, for instance: a) F. Pérez-Balderas, M. Ortega-Muñoz, J. Morales-Sanfrutos, F. Hernández-Mateo, F. G. Calvo-Flores, J. A. Calvo-Asín, J. Isac-García, F. Santoyo-González, Org. Lett. 2003, 5, 1951-1954; b) P. Appukkuttan, W. Dehaen, V. V. Fokin, E. Van der Eycken, Org. Lett. 2004, 6, 4223-4225; c) H. S. G. Beckmann, V. Wittmann, Org. Lett. 2007, 9, 1-4; d) F. Pisaneschi, F. M. Cordero, M. Lumini, A. Brandi, Synlett 2007, 2882-2884; e) for a recent microreview, see: P. Appukkuttan, E. Van der Eycken, Eur. J. Org. Chem. 2008, 1133-1155; f) A. D. Moorhouse, J. E. Moses, Synlett 2008, 2089-2092.

[15] B. Sreedhar, P. S. Reddy, Synth. Commun. 2007, 37, 805-812.

[16] See, for instance: a) B. H. Lipshutz, B. R. Taft, Angew. Chem. Int. Ed. 2006, 45, 8235-8238; b) S. Chassaing, A. S. S. Sido, A. Alix, M. Kumarraja, P. Pale, J. Sommer, Chem. Eur. J. 2008 , 14, 6713-6721; c) T. Miao, L. Wang, Synthesis 2008, 363-368; d) U. Sirion, Y. J. Bae, B. S. Lee, D. Y. Chi, Synlett 2008, 23262330.

[17] C. D. Smith, I. R. Baxendale, S. Lanners, J. J. Hayward, S. C. Smith, S. V. Ley, Org. Biomol. Chem. 2007, 5, 1559-1561.

[18] a) F. Himo, T. Lovell, R. Hilgraf, V. V. Rostovtsev, L. Noodleman, K. B. Sharpless, V. V. Fokin, J. Am. Chem. Soc. 2005, 127, 210-216; b) N. Gommermann, A. Gehrig, P. Knochel, Synlett 2005, 2796-2798.

[19] a) L. Durán Pachón, J. H. van Maarseveen, G. Rothenberg, Adv. Synth. Catal. 2005, 347, 811-815; b) H. A. Orgueira, D. Fokas, Y. Isome, P. C.-M. Chan, C. M. Baldino, Tetrahedron Lett. 2005, 46, 2911-2914; c) M. Laksmi Kantam, V. Swarna Jaya, B. Sreedhar, M. Mohan Rao, B. M. Choudary, J. Mol. Catal. A 2006, 256, 273-277; d) G. Molteni, C. L. Bianchi, G. Marinoni, N. Santo, A. Ponti, New J. Chem. 2006, 30, 1137-1139; e) A. Sarkar, T. Mukherjee, S. Kapoor, J. Phys. Chem. C 2008, 112, 3334-3340; f) I. S. Park, M. S. Kwon, Y. Kim, J. S. Lee, J. Park, Org. Lett. 2008, 10, 497-500; g) H. Sharghi, R. Khalifeh, M. M. Doroodmand, Adv. Synth. Catal. 2009, 351, 207-218.

[20] For reviews, see: a) F. Alonso, G. Radivoy, M. Yus, Russ. Chem Bull. Int. Ed. 2003, 52, 2563-2576; b) F. Alonso, M. Yus, Chem. Soc. Rev. 2004, 33, 284-293; c) F. Alonso, M. Yus, Pure Appl. Chem. 2008, 80, 1005-1012.

[21] a) F. Alonso, C. Vitale, G. Radivoy, M. Yus, Synthesis 2003 , 443-447; b) F. Alonso, Y. Moglie, G. Radivoy, C. Vitale, M. Yus, Appl. Catal. A: Gen. 2004, 271, 171-176; c) G. Radivoy, F. Alonso, Y. Moglie, C. Vitale, M. Yus, Tetrahedron 2005, 61, 3859-3864.

[22] F. Alonso, Y. Moglie, G. Radivoy, M. Yus, Tetrahedron Lett. 2009, 50, 2358-2362

[23] a) R. D. Rieke, L. D. Rhyne, J. Org. Chem. 1979, 44, 34453446; b) R. D. Rieke, M. S. Sell, W. R. Klein, T. Chen, J. D. Brown, M. V. Hanson in Active Metals (Ed.: A. Fürstner), VCH, Weinheim, 1996, pp. 33-48.

[24] See, for instance: a) N. A. Dhas, C. P. Raj, A. Gedanken, Chem. Mater. 1998, 10, 1446-1452; b) S. U. Son, I. K. Park, J. Park, T. Hyeon, Chem. Commun. 2004, 778-779; c) A. A. Ponce, K. J. Klabunde, J. Mol. Catal. A 2005, 225, 1-6.

[25] See, for instance: a) H. H. Huang, F. Q. Yan, Y. M. Kek, C. H. Chew, G. Q. Xu, W. Ji, P. S. Oh, S. H. Tang, Langmuir 1997, 13, 172-175; b) A. C. Curtis, D. G. Duff, P. P. Edwards, D. A. Jefferson, B. F. G. Johnson, A. I. Kirkland, A. S. Wallace, J. Phys. Chem. 1988, 92, 2270-2275; c) S.-H. Wu, D.-H. Chen, J. Colloid Interface Sci. 2004, 273, 165-169; d) H. Zhu, C. Zhang, Y. Yin, Nanotechnology 2005, 16, 3079-3080; e) M. Kidwai, V. Bansal, N. K. Mishra, A. Kumar, S. Mozumdar, Synlett 2007, 1581-1584; f) M. Takahashi, J. Kamada, K. Iwata, K. Goto, H. Watanabe, S. Tamai, Bull. Chem. Soc. Jpn. 2008, 81, 168170.

[26] a) G. Vitulli, M. Bernini, S. Bertozzi, E. Pitzalis, P. Salvadori, S. Coluccia, G. Martra, Chem. Mater. 2002, 14, 1183-1186; b) T. N. Rostovshchikova, V. V. Smirnov, V. M. Kozhevin, D. A. Yavsin, M. A. Zabelin, I. N. Yassievich, S. A. Gurevich, Appl. Catal. A: Gen. 2005, 296, 70-79; c) T. Nakamura, Y. Tsukah-
546 
ara, T. Sakata, H. Mori, Y. Kanbe, H. Bessho, Y. Wada, Bull. Chem. Soc. Jpn. 2007, 80, 224-232.

[27] a) F. L.-Y. Lam, Y. Zhang, X. Hu, P. Sheng, Z. Yan, International Conference on Nanoscience and Nanotechnology, ICONN 2006, Brisbane, Australia, pp. 15-18; b) S. Bhadra, A Saha, B. C. Ranu, Green Chem. 2008, 10, 1224-1230.

[28] a) N. Toshima, Y. Wang, Langmuir 1994, 10, 4574 4580; b) A. F. Carley, L. A. Dollard, P. R. Norman, C. Pottage, M. W. Roberts, J. Electron Spectrosc. Relat. Phenom. 1999, 98-99, 223-233; c) M. Laksmi Kantam, S. Laha, J. Yadav, P. R. Likhar, B. Sreedhar, B. M. Choudary, Adv. Synth. Catal. 2007, 349, 1797-1802.

[29] A. K. Feldman, B. Colasson, K. B. Sharpless, V. V. Fokin, J. Am. Chem. Soc. 2005, 127, 13444-13445.

[30] CCDC-752783 contains the supplementary crystallographic data for this paper. These data can be obtained free of charge from The Cambridge Crystallographic Data Centre via www.ccdc.cam.ac.uk/data_request/cif.

[31] D. C. Owsley, C. E. Castro, Org. Synth. 1972, 52, 128-131.

[32] a) K. Sonogashira, J. Organomet. Chem. 2002, 653, 46-49; b) R. Chinchilla, C. Nájera, Chem. Rev. 2007, 107, 874-922.

[33] a) M. Ahlquist, V. V. Fokin, Organometallics 2007, 26, 43894391; b) B. F. Straub, Chem. Commun. 2007, 3868-3870; c) C. Nolte, P. Mayer, B. F. Straub, Angew. Chem. Int. Ed. 2007, 46 , 2101-2103.

[34] a) V. A. Sazonova, N. Y. Kronrod, J. Gen. Chem. U.S.S.R. (Engl. Transl.) 1956, 26, 2093-2097; b) C. E. Castro, R. D. Stephens, J. Org. Chem. 1963, 28, 3313-3315.

[35] J. T. Yoke III, J. F. Weiss, G. Tollin, Inorg. Chem. 1963, 2, 1210 1216.

Received: December 11, 2009 
The 1,3-dipolar cycloaddition of terminal alkynes and azides catalysed by readily generated copper nanoparticles is reported. Reactions are fast and lead to the corresponding triazoles in good-to-excellent yields. A reaction mechanism involving copper(I) acetylides was proposed on the

$$
\begin{gathered}
\mathrm{R}^{1}-\mathrm{N}_{3}+\equiv \mathrm{R}^{2} \\
\text { CunPs }(10 \mathrm{~mol}-\mathrm{\%}) \\
\mathrm{Et}_{3} \mathrm{~N}, \mathrm{THF}, 65^{\circ} \mathrm{C} \\
10-120 \mathrm{~min}
\end{gathered}
$$

F. Alonso,* Y. Moglie, G. Radivoy,

M. Yus*

1-11

Unsupported Copper Nanoparticles in the 1,3-Dipolar Cycloaddition of Terminal Alkynes and Azides

Keywords: Click chemistry / Cycloaddition / Alkynes / Azides / Copper / Nanoparticles 